\title{
An Unusually Large Submandibular Salivary Stone
}

\author{
${ }^{1}$ Sushma Pandey, ${ }^{2}$ Sushil Subedi, ${ }^{3}$ Rohit Gadda
}

\begin{abstract}
Sialolithiasis is a condition where a calcified mass forms within a salivary gland, most commonly in the duct of the submandibular gland. Commonly sialoliths measure from 5 to $10 \mathrm{~mm}$ in size and stones over $10 \mathrm{~mm}$ can be reported as sialoliths of unusual size. They rarely measure more than $15 \mathrm{~mm}$. Reported here is a case of large submandibular sialolith which was diagnosed clinically and radiographically and treated with no postoperative complications.
\end{abstract}

Keywords: Submandibular gland, Sialolithiasis, Calculi, Stones.

How to cite this article: Pandey S, Subedi S, Gadda R. An Unusually Large Submandibular Salivary Stone. J Contemp Dent 2014;4(3):160-161.

Source of support: Nil

Conflict of interest: None

\section{INTRODUCTION}

Sialoliths are calcareous concretions that may be found in the ducts of the major or minor salivary glands or within the glands themselves. They are thought to form by deposition of calcium salts around a central nidus which may consist of desquamated epithelial cells, bacteria, products of bacterial decomposition or foreign bodies. ${ }^{1}$ Sialolithiasis is the most common (50\%) disease of salivary glands. Its estimated frequency is $1.2 \%$ in the adult population every year, with a slight male predominance (2:1). ${ }^{3}$ Most salivary calculi occur in the submandibular gland $(80-95 \%)$, whereas 5 to $20 \%$ occur in the parotid gland. The sublingual gland and minor salivary glands are rarely (1-2\%) affected. ${ }^{2}$ Salivary calculi are usually unilateral. Clinically, they are round or ovoid, rough or smooth with yellow in color. ${ }^{2}$ About $40 \%$ of parotid and $20 \%$ of submandibular stones are not radiopaque, and sialography or other imaging techniques (computed

\footnotetext{
${ }^{1-3}$ Assistant Professor

${ }^{1}$ Department of Oral Medicine and Radiology, Chitwan Medical College, Bharatpur, Chitwan, Nepal

${ }^{2}$ Department of Oral and Maxillofacial Surgery, Chitwan Medical College, Bharatpur, Chitwan, Nepal

${ }^{3}$ Department of Oral Medicine and Radiology, MGM Dental College and Hospital, Navi Mumbai, Maharashtra, India

Corresponding Author: Sushma Pandey, Assistant Professor Department of Oral Medicine and Radiology, Chitwan Medical College, Bharatpur, Chitwan, Nepal, Phone: 97714411393 e-mail: pandeysusma@gmail.com
}

tomography scan, ultrasound) may be required to locate them. ${ }^{4}$ Commonly, sialoliths measure from 5 to $10 \mathrm{~mm}$ in size and stones over $10 \mathrm{~mm}$ can be reported as sialoliths of unusual size. They rarely measure more than $15 \mathrm{~mm}$.

\section{CASE REPORT}

A 17-year-old female residing in Chitwan, reported with a complaint of a pain and swelling in the posterior part of left side of the floor of the mouth for a duration of 2 months. There were episodes of pain in the same region for last 2 years but of a moderate variety that the patient could tolerate. Her pain was intermittent, pricking type and sharp in nature and it was radiating to the tongue. The pain was aggravated during eating and relieved at rest. Swelling was gradual in onset, progressed to the presented size. There were occasions of increase in swelling during meals for the last 6 months, which the patient had been ignoring. There was no associated history of fever, malaise, weight loss, anorexia or burning sensation in the oral cavity. Her family history was non-contributory. On general examination, she appeared to be in a good overall systemic health. Extraoral examination findings were not contributory. Intraoral examination showed inflammation and sinus opening over the left floor of the mouth in the posterior aspect (Fig. 1) with absent of salivary flow from the left Wharton's duct orifice. However, no pus discharge was detected from the duct orifice. The left submandibular gland was tender on bimanual palpation. Interestingly, it also revealed yellowish mass coming out from the sinus on applying upward pressure during palpation.

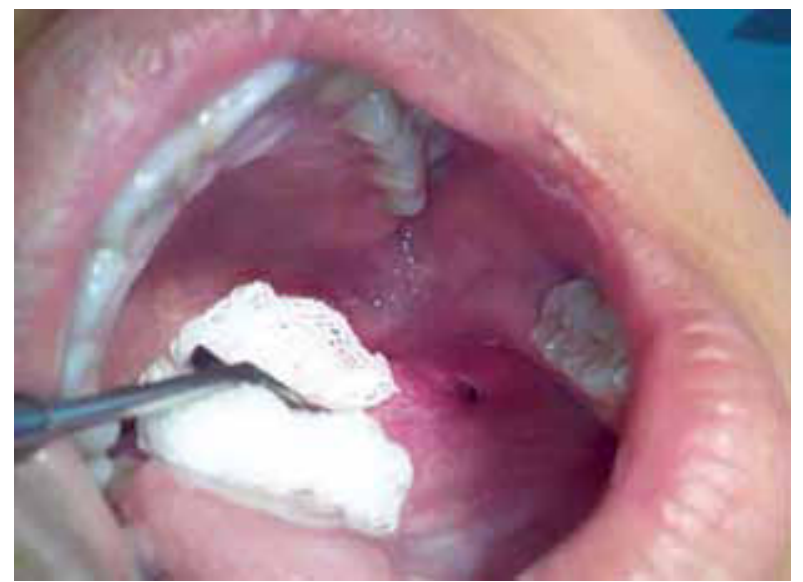

Fig. 1: Inflammation and sinus opening over the left floor of the mouth in the posterior aspect 
A lower occlusal radiograph was advised but because of posteriorly placed lesion, nothing could be seen. Hence, CT scan was advised, and it showed a calcified lesion in left submandibular gland, measuring approximately $1.2 \times 0.7 \mathrm{~cm}$ in size (Fig. 2). A diagnosis of left submandibular duct calculus was made and, at a subsequent appointment, it was removed under local anesthesia with sharp dissection. It was measured to be $15 \mathrm{~mm}$ long along its greatest length (Fig. 3). Patient was reviewed 2 weeks postoperatively to check salivary function of the gland. Healing of the surgical wound and salivary flow was found normal, postoperatively.

\section{DISCUSSION}

Submandibular sialoliths measuring less than $10 \mathrm{~mm}$ in greatest dimension are very common but larger sialoliths are considerably less. ${ }^{5}$ The ability of a calculus to grow and become a giant sialolith depends mainly on the reaction of the affected duct. If the duct adjacent to the sialolith is able to dilate, allowing nearly normal secretion of saliva around the stone, it might be asymptomatic for a long period and eventually a giant calculus will be created. ${ }^{6}$ A sialo-oral fistula develops most likely when bacteria set up an acute exacerbation in the stagnating and retained saliva located behind the stone. The inflammatory debris obstructs the residual narrowed duct lumen, further exacerbating the inflammation. The resulting inflammatory process around a large stone may lead to tissue breakdown and spontaneous stone extrusion with intraoral fistula formation.

Careful history and examination are important in the diagnosis of sialolithiasis. Pain and swelling of the concerned gland at mealtimes and in response to other salivary stimuli are especially important. Bimanual palpation of the floor of the mouth, in a posterior to anterior direction, reveals a palpable stone in a large number of cases of submandibular calculi.

\section{CONCLUSION}

Submandibular sialoliths measuring less than $10 \mathrm{~mm}$ in greatest dimension are very common but larger sialoliths are considerably less. Moreover, some sialolithiasis are so posteriorly placed that $\mathrm{CT}$ images required than common conventional occlusal radiographs. Reported here is a case of submandibular sialolith which was diagnosed clinically and radiographically and treated surgically with no postoperative complications.
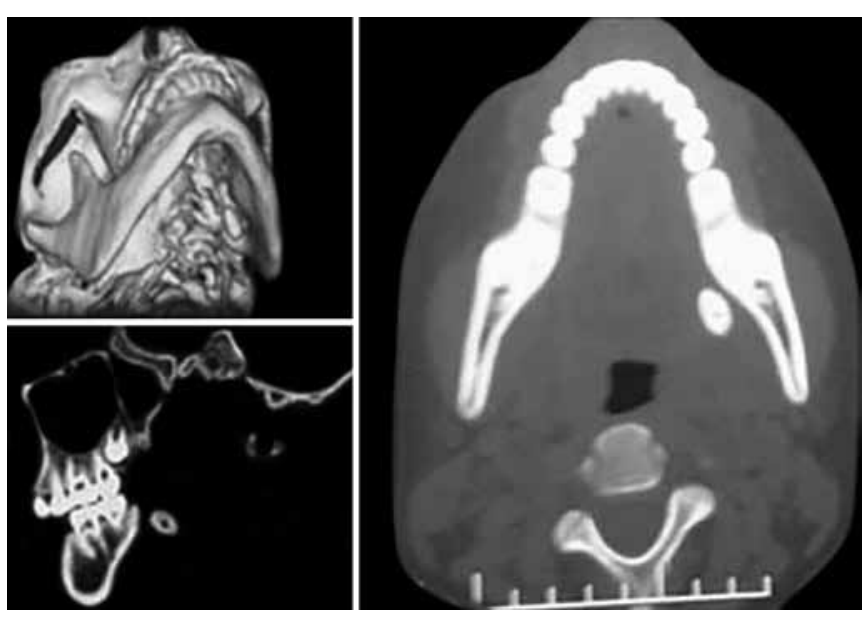

Fig. 2: CT scan images (axial, sagittal, 3D ) showing a calcified lesion in left submandibular gland

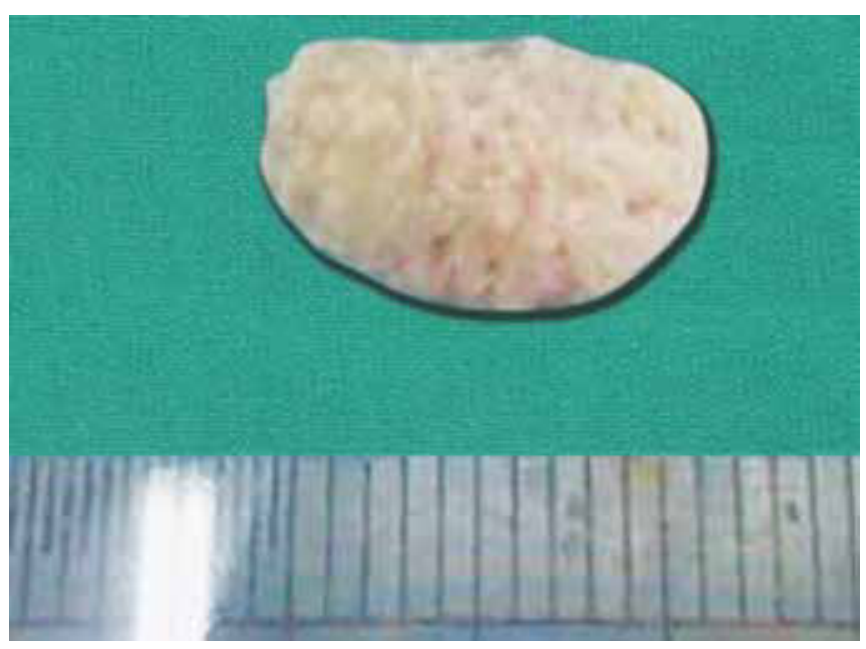

Fig. 3: Sialolith with approximately $15 \mathrm{~mm}$ long along its greatest length

\section{REFERENCES}

1. Shafer WG, Hine MK, Levy BM. Physical and chemical injuries of the oral cavity. In: A Textbook of Oral Pathology. 4th ed. Philadelphia: WB Saunders Co; 1983. p. 561.

2. Siddiqui SJ. Sialolithiasis and unusually large submandibular salivary stone. Br Dent J 2002;193(2):89-91.

3. Zenk J, Constantinidis J, A1-kadah B, Heinnch ko. Transoral removal of submandibular stones. Arch Otolaryngoal Head Neck Surg 2001;127(4):432-436.

4. Andretta M, Tregnaghi A, Prosenikhev V, Staftien K. Current opinions in sialolithiasis diagnosis and treatment. Acta Otorhinolaryngol Hal 2005;25(3):145-149.

5. Huang TC, Dalton JB, Monsour FN, Savage NW. Multiple, large sialoliths of the submandibular gland duct: a case report. Aus Dent J 2009;54(1):1-65.

6. Paul D, Chauhan MS. Salivary megalith with a sialocutaneous and sialo-oral fistula: a case report. J Laryngol Otol 1995; 109(8):767-769. 